\title{
Advances in the pathogenesis and treatment of nut carcinoma: a narrative review
}

\author{
Sanchun Wang, Jinqiu Li, Weifang Tong, Hejie Li, Qingjie Feng, Bo Teng \\ Department of Otorhinolaryngology Head and Neck Surgery, The Second Hospital of Jilin University, Changchun, China \\ Contributions: (I) Conception and design: S Wang; (II) Administrative support: B Teng; (III) Provision of study materials or patients: All authors; (IV) \\ Collection and assembly of data: All authors; (V) Data analysis and interpretation: S Wang; (VI) Manuscript writing: All authors; (VII) Final approval \\ of manuscript: All authors. \\ Correspondence to: Bo Teng, PhD. Department of Otorhinolaryngology Head and Neck Surgery, The Second Hospital of Jilin University, Changchun \\ 130021, China. Email: tengbo1975@163.com.
}

\begin{abstract}
NUT carcinoma (NC) is a rare, highly invasive and fatal tumor and often misdiagnosed. It typically arises from the mediastinum and midline organs and has complicated pathogenesis and poor outcome. Genetically, its pathogenesis is related to a chromosomal rearrangement involving the NUTM1 gene. In most cases, the main oncoprotein is BRD4-NUT with a translocation between NUTM1 and BRD4 genes, but in a few cases, the oncoprotein is BRD3-NUT, or NSD3-NUT. Studies have shown that the histone hyperacetylation and BRD4 hyperphosphorylation may lead to the activation of cancer circuits. Abnormal production of microRNA, inactivation of tumor suppressor genes and abnormal activation of several signaling pathways are proposed as potential mechanisms underlying the pathogenesis of NC. Currently, there is no consensus on its standard treatment for NC. Extent of surgical resection with negative margins, initial radiotherapy and part of chemotherapy regimens may significantly associated with the improvement of progression-free survival (PFS) rate and overall survival (OS) rate. Some bromodomain and extraterminal inhibitors (BETis) have shown encouraging results in the clinical trials on NC, but delayed drug resistance is still an important issue that needs to be resolved. Histone deacetylase inhibitors are also found to possess the potential in the treatment of NC. Herein, we summarize recent advances in the pathogenesis and treatment of NC.
\end{abstract}

Keywords: NUT carcinoma (NC); pathogenesis; gene rearrangement; therapy; bromodomain and extraterminal inhibitors (BETis)

Submitted Apr 20, 2020. Accepted for publication Sep 12, 2020.

doi: $10.21037 /$ tcr-20-1884

View this article at: http://dx.doi.org/10.21037/tcr-20-1884

\section{Introduction}

NUT midline carcinoma (NMC) is a malignant tumor with involvement of testicular nuclear gene rearrangement, which has the tendency to arise from midline anatomical sites, and it was initially described as a mediastinal tumor in 1991 (1) with increasing cases reported in nonmidline structure such as renal pelvis, pancreas, parotid gland, bladder, sublingual gland and femur (2-7). WHO redefined NMC as NUT carcinoma (NC) in 2015 (8). Generally, NC progresses rapidly. Bauer et al. investigated the clinical characteristics of 57 patients with $\mathrm{NC}$ and found that the median survival time was 6.7 months (9). Pathologically, NC is characterized by variable degrees of squamous differentiation with a predominance of the poorly or undifferentiated component $(10,11)$. The pathogenesis of $\mathrm{NC}$ is complex and related to the acquired chromosomal rearrangements involving NUTM1 (NUT Carcinoma Family Member 1) and other causes leading to the differentiation blocking (12). NC has no preference for gender or age and is often misdiagnosed. The survival rate of NC patients has not been improved significantly 
although some strategies have been employed for the treatment of $\mathrm{NC}$, and there is no consensus on the standard treatment for NC currently. Herein, we summarize the advances in the pathogenesis and treatment of NC in recent years. We present the following article in accordance with the Narrative Review reporting checklist (available at http://dx.doi.org/10.21037/tcr-20-1884).

\section{Pathogenesis}

\section{Exposure factors}

The occurrence of NC has not been reported to be associated with any special exposure factors such as tobacco use (13) and infection with Epstein-Barr virus or human papillomavirus $(14,15)$. Whether the occurrence of $\mathrm{NC}$ is related to other tumor-causing viral infections is needed to be further studied.

\section{Multiple gene rearrangement}

Malignant tumors may be caused by genetic changes, including the acquisition or loss of chromosomes and chromosomal segments, gene translocation, gene transcoding, and gene point mutations, which can lead to the activation of oncogenes or inactivation of tumor suppressor gene (TSG). Shiota et al. found that NUT is expressed in post-meiotic spermatogenic germ cells, and it can recruit p300 and/or CBP and enhance histone H4K5 and $\mathrm{H} 4 \mathrm{~K} 8$ acetylation, leading to the histone-to-protamine replacement (16). In the rearrangement gene expression of NC, the NUTM1 (NUT) gene usually uses bromodomaincontaining protein 4 (BRD4) as a fusion partner, sometimes uses BRD3, and, in a few cases, uses NSD3 $(17,18)$. Alekseyenko et al. found that ZNF532 as a chromatin factor could interact with BRD4-NUT complexes, and they also identified another fusion oncogene, ZNF532-NUT (19). It has been reported abnormal three-way translocations involving $\mathrm{t}(4 ; 15 ; 19), \mathrm{t}(9 ; 15 ; 19), \mathrm{t}(11 ; 15 ; 19)$ and a $\mathrm{t}(2 ; 9 ; 15)$ in NC cells (20). A new type of NUT fusion partner $M G A$ has also been reported $(21,22)$, but this pathology is ultimately classified as a sarcoma; MXD4, a novel partner, is reported recently $(21,23)$.

Lee et al. sequenced the whole genome and transcriptome of three NC patients and found that, except for BRD3/4NUT oncogene rearrangement, no canonical oncogenes or tumor suppressor genes were affected, but it caused NC, a fatal disease (13). French et al. for the first time reported the fusion oncogene, BRD4-NUT in 2003 (24). The expression of NUT fusion oncogenes has great heterogeneity at different ages and tumor locations, which indicates that $\mathrm{NC}$ may eventually be divided into clinically related subgroups with different clinical outcomes and therapeutic responses (25). Chau et al. grouped 124 out of $141 \mathrm{NC}$ patients by anatomic location and fusion type, and nonthoracic primary NC group with non-BRD4-NUT fusion had the best outcome (26). Testing for NC rearrangement may be not enough, and the identification of specific fusion partners may be necessary to develop therapeutic strategies.

\section{Histone hyperacetylation and BRD4 hyperphosphorylation}

NUT is exclusively expressed in the testis of human and mice, and p300 and/or CBP are the only acetyltransferases present in the NUT interactome. NUT recruits p300 and/ or CBP to control histone $\mathrm{H} 3$ and $\mathrm{H} 4$ acetylation. In NC cells, a chromosomal translocation induces NUT-mediated forced cooperation between $\mathrm{p} 300$ and/or CBP and BRD4, forming the hyperacetylated histone chromatin foci (16). This acetylation further affects BRD4-NUT in a synergistic manner, ultimately forming a large number of acetylated chromatin regions covering various topologically relevant domains of the entire genome, called the megadomain (27). The megadomain contains approximately 100 chromatin domains, ranging from 100 to $2,000 \mathrm{~kb}$, across the gene and intergenic regions (28).

$B R D 4$ is a member of the bromodomain and extraterminal (BET) family. The tandem bromodomains of $B R D 4$ (BD1 and BD2) can specifically recognize acetylated histones $\mathrm{H} 3$ and $\mathrm{H} 4$ on chromatins (29). $B R D 4$ has been implicated in the pathogenesis of a variety of cancers, including hematological malignancies and solid tumors (30-33). It is also the target of genetic translocation between chromosomes 15 and 19, expressed as $\mathrm{t}(15 ; 19)$, which leads to the formation of a novel fusion oncogene BRD4-NUT (24). BRD4-NUT can induce the abnormal activation of oncogenes such as SOX2 (34) and c-MYC (35) in the hyperacetylated chromatin in NC cells. Wang et al. found that a unique cellular environment induced BRD4 hyperphosphorylation in HCC2429 NC cells. The hyperphosphorylation of BRD 4 induced by $B R D 4-N U T$ may contribute to the transactivation of oncogenes, which accounts for NC transformation (36).

SOX2 is a sex-determining region Y-box protein 2 and mainly expressed in the stem cells. SOX2 is an essential transcription factor for the self-renewal and pluripotency 
of stem cells (37). SOX2 mutations induce abnormal self-renewal of stem cells, leading to the abnormal differentiation of stem cells $(37,38)$. BRD4-NUT induces abnormally high SOX2 expression in the NC cells to promote the abnormal stem cell-like growth, which is the basis for the highly invasive transformation activity of the $\mathrm{t}(15 ; 19)$ translocation (34).

$M Y C$ up-regulation is a common driving event in some human cancers. $M Y C$ can maintain the transcriptional programs to promote cell growth and proliferation. Grayson et al. found that BRD4-NUT prevented the differentiation of NC by maintaining $M Y C$ expression (35). The ability of BRD4-NUT to diffuse and fill the entire regulatory region of $M Y C$ gene and other genes may explain the aggressiveness of $\mathrm{NC}$.

\section{MicroRNA (miRNA) amplification}

miRNAs play a key role in regulating target genes and are involved in the development and progression of cancers. miRNAs refer to a group of non-coding RNAs approximately 21 nucleotides in length that can inhibit the expression of target genes by binding to complementary mRNA. A single miRNA can regulate the expression of some different mRNAs $(39,40)$. Pathak et al. compared the miRNAs that target BRD4 and NUT transcribed regions before and after $B R D 4-N U T$ gene fusion event. Because of the formation of fusion transcripts, the regions of fusion gene deletion will no longer be the targets for their respective miRNAs. Many such ex-miRNAs will be significantly amplified in cancer cells, resulting in abnormal cell behaviors (41). miR-3140 (a novel tumor suppressor miRNA) directly inhibits the expression of BRD 4 by binding to its coding sequence; it also inhibits the BRD4NUT fusion protein and its downstream target $M Y C$ in the NC cell lines (42).

\section{Inactivity of TSG}

TP53 is a powerful tumor suppressor gene that prevents mutation via DNA repair and inducing apoptosis. There is evidence showing that BRD4-NUT promotes acetylation of $\mathrm{p} 53$ via $\mathrm{p} 300$, resulting in the chelation and inactivation of BRD4-NUT (43). It inhibits SOX2 significantly by inhibiting the p300 activity (44); mRNA and protein expressions of $c-M Y C$ are also reduced. Alekseyenko et al. found that the expression of TP53-associated squamous cell gene TP63 was regulated by the BRD4-NUT megadomain in all tested NCs, which supports a possible mechanism by which BRD4-NUT can evade the gatekeeper function of p53 (27).

\section{Abnormal activation of signaling pathways}

MYC maintains the proliferation and undifferentiated state of tumor cells in NC. The blockade of PI3K signaling pathway may inhibit MYC activity by suppressing $M Y C$ gene transcription and protein activity or down-regulating apoptosis of $M Y C$-dependent NC cells (44). The activation of RTK, GPCR, and cAMP/PKA signaling pathways are also found to mediate the resistance to BET inhibitors (BETis) in NC cells (45).

\section{Treatment}

\section{Surgery and radiotberapy}

$\mathrm{NC}$ is a highly invasive tumor for which there is no consensus on its standard treatment (6,46-56) (Table 1). It has been reported that extent of surgical resection and initial radiotherapy are the independent predictors of progression-free survival (PFS) rate and overall survival (OS) rate of NC patients (9). A recent study on 48 patients with head and neck NC reported that the only long-term survivors in the study were patients who achieved an early complete remission after initial surgery (57). Radiotherapy as a part of the initial treatment may has a positive impact on the OS rate. However, studies shows that radiotherapy has a positive effect on tumors that originate from the head, neck and lungs, but not on the mediastinal primary tumors (58).

\section{Chemotherapy}

Currently, several drugs have been used for the chemotherapy of NC, including cisplatin, carboplatin, cyclophosphamide, etoposide, doxorubicin, actinomycin D, vinorelbine, vinblastine, paclitaxel, docetaxel, 5-fluorouracil, $\mathrm{S} 1$, bleomycin, vincristine, ifosfamide, gemcitabine and BETis (58). Beesley et al. found that vincristine significantly reduced the tumor burden in NC xenografts and was, therefore, an effective drug for the treatment of $\mathrm{NC}$. However, although vincristine significantly slowed tumor growth in these models, it was not sufficient to prevent tumor recurrence (59). Etoposide and vorinostat have also been used in NC patients. Vincristine, doxorubicin, and 


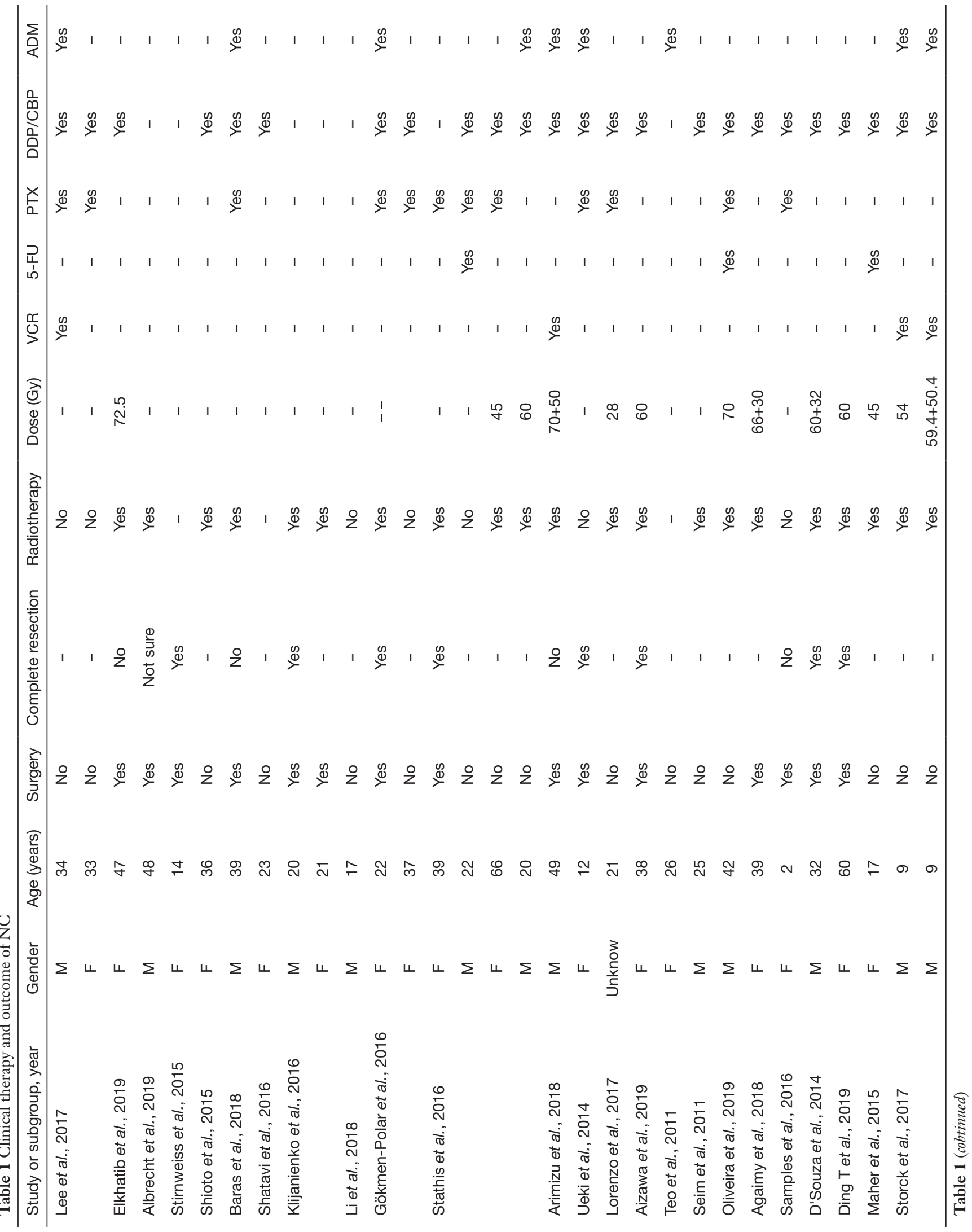




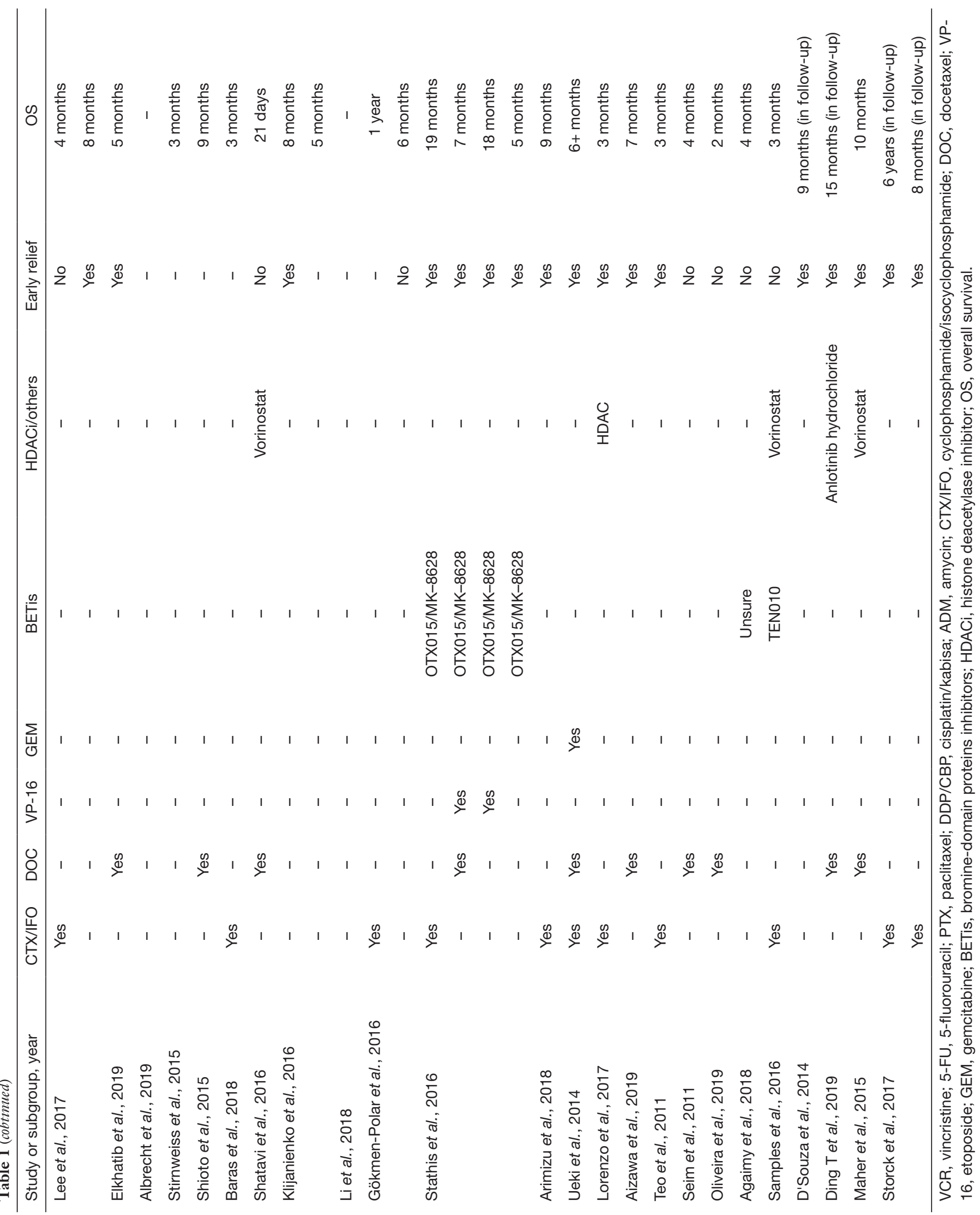


flavopiridol (CDK9 inhibitor) show significantly better activity than etoposide and vorinostat; statins and antimetabolites exhibit moderate monotherapy efficacy (59).

In two case reports, three pediatric NC patients were treated with a comprehensive protocol for sarcoma (SSG IX), involving surgery, chemotherapy and focal radiotherapy. These three patients experienced remission for 6 years, 14 years, and 13 years, respectively $(60,61)$.

\section{Targeted therapy}

\section{BET inhibitors}

A BETis is an acetyl histone mimetic that specifically binds to the BET bromodomain and competitively inhibits its binding to the chromatin (62). In early studies, BETis were shown to be effective against murine hematological malignancies (63). In recent years, many studies have shown that BETis is also effective to inhibit the progression of non-hematological malignancies $(64,65)$. The anti-tumor effect of BETis has also been confirmed in NC. NC cells always have at least one intact $B R D 4$ locus and express normal BRD4 and BRD-NUT oncoproteins. A variety of BETis are used in clinical trials for the treatment of $\mathrm{NC}$, such as OTX105/MK-8628, GSK525762 and others (such as BAY1238097, GSK2820151, and TEN-010) $(62,64,66)$. Early clinical trials have shown encouraging results $(67,68)$, especially for hematologic malignancies (34). Pathological examination after tumor biopsy revealed a decreased NUT expression in areas of differentiation in a NC patient after BETis treatment. This indicates that NC cells may switch to a more differentiated squamous cell phenotype after BETis treatment is initiated. The degree of squamous cell differentiation after BETis treatment may be caused by a number of factors, including the duration of treatment and the site of recurrence (69).

JQ1 is a first-generation BETis. CDK4/6 inhibitors and JQ1 have been used synergistically in vitro in NC. Endogenous CDK4/6 plays an important role in regulating JQ1 sensitivity, and CDK4/6 inhibitors may exert synergetic effect with JQ1 (45). A study shows that BET inhibitor JQ1 can induce the differentiation and growth arrest in $\mathrm{NC}$ cell lines, and also exert anti-tumor effect in xenograft models of NC (70-72).

The small-molecule BETis birabresib (OTX015/ MK-8628) shows anti-tumor activity in patients with hematological malignancies. Lewin et al. evaluated the safety and effectiveness of OTX015 in a dose escalation study. Three of 10 patients with NC achieved partial remission.
Pharmacokinetic analysis showed that OTX015 exposure and rapid absorption were associated with a dose ratio increase, which suggests OTX015 has good safety in the treatment of solid tumors $(66,67)$. BETis in patients with BRD3-NUT or NSD3-NUT has similar pharmacodynamic effects; this is the first proof of concept for the clinical activity of bromodomain inhibitors targeting NC (66).

BETis have reversible adverse effects, including fatigue, headache, thrombocytopenia (66), diarrhea, fatigue, nausea, dyspepsia, and hyperglycemia. The pervasive apoptosis in intestinal cells has also been observed after treatment with BETis, which may exacerbate the chemotoxic damage or radiation induced injury (73).

\section{Resistance to BETis}

BETis are effective against NC. However, not all NC patients respond to BETis, and the responders will eventually develop resistance and relapse (45). Studies have shown that some refractory cancers are resistant to BETis (74), including $\mathrm{NC}$ (42). In some models, resistant cells continue to rely on $c-M Y C$ to drive proliferation, but in case of BETis resistance, resistant cells will switch from BRD4-mediated $M Y C$ expression to other pathways, including GLI2 or WNT$\beta$-catenin signaling, to maintain $M Y C$ expression (45). $\mathrm{NC}$ cells have many potential pathways for maintaining $M Y C$ function. ERK and AKT inhibitors can inhibit the expression of downstream signaling pathways of RRAS2 (Ras-associated GTPase). JQ1 can significantly reduce the expression of $c-M y c$ and cyclin D1, whereas RRAS2 largely restores the phosphorylation of ERK and increases the expression of $c-M y c$ and cyclin D1. KLF4 (a transcription factor containing a zinc finger structure) mediates JQ1 resistance in NC cells, and KLF4 cells are able to maintain $M Y C$ and $E 2 F$ gene expression under JQ1 treatment and bypass JQ1-induced cell cycle arrest (45). The activation of RTK signaling pathway or GPCR/ cAMP/PKA signaling pathway can also mediate BETis resistance in $\mathrm{NC}$ cells. Cell cycle regulators also play an important role in mediating the carcinogenesis of BRD4NUT (45). Treatment with PI3KCA inhibitors can induce the sensitivity of drug-resistant cells to JQ1 (75). Binding of a BET inhibitor to a PI3K inhibitor maintains PI3K inhibition and enhances cell killing activity (76). In the drug-resistant cells, the bromodomain of $B R D 4$ is activated and thus it is unaffected by BETis (77).

Histone deacetylase inbibitor (HDACi) and small molecules 
Preclinical studies have shown that the upstream modulators, targeting $M Y C$ alone, such as histone deacetylase (HDAC) and phosphoinositide 3-kinase (PI3K), can reduce $M Y C$ protein expression and inhibit $M Y C$ driven carcinogenesis. CUDC-907 is a small-molecule, double-acting inhibitor of class I and class II HDACs and class I PI3K. It is effective to inhibit the growth and survival of $M Y C$-modified or $M Y C$-dependent cancer cells and may be used as a potential therapy for $M Y C$-dependent cancer. At present, the safety, tolerability, and pharmacokinetic assessments of CUDC-907 have yielded encouraging results in clinical trials (44).

Vorinostat is a histone deacetylase inhibitor (HDACi), and studies have shown that vorinostat can induce tumor cell differentiation and inhibit tumor growth, including NC $(78,79)$.

CDK9 is a potential kinase that mediates $B R D 4$ hyperphosphorylation. CDK9 inhibitors can block BRD4 hyperphosphorylation in the $\mathrm{NC}$ cells, and a dominant negative inhibitor of $B R D 4$ and $C D K 9$ interaction has been found to abolish $B R D 4$ hyperphosphorylation, oncogene expression, and cell transformation in NC (36). CDK9i and bromodomain inhibition lead to the decrease of $M Y C$ protein expression, but only bromodomain inhibition induces cell differentiation (80).

Anlotinib hydrochloride is a novel small-molecule, multi-target tyrosine kinase inhibitor that potently inhibits kinases such as vascular endothelial growth factor receptor, platelet-derived growth factor receptor, fibroblast growth factor receptor, and c-Kit. A patient with $\mathrm{NC}$ was relieved after radiotherapy combined with anlotinib hydrochloride. However, more evidence is needed to confirm the therapeutic effect of anlotinib hydrochloride on NC (81).

NC can develop of all ages without gender preference. Only a few patients responded to the treatment, including pediatric cases $(52,60,61,66,82)$. Wang et al. found that children with salivary gland NUT carcinomas represented a distinct subset with male predilection and better overall survival (83). However, due to the small number of cases responding to the treatment, it is not enough to explain the difference in the therapeutic effect between children and adults, and more evidence is needed to confirm this result.

\section{Conclusions}

$\mathrm{NC}$ is a rare disease and often misdiagnosed due to nonspecific pathological and clinical manifestations. It should be considered to avoid misdiagnosis and delayed treatment once poorly differentiated tumor is encountered. The pathogenesis of NC is complicated. At present, there is no consensus on the standard clinical treatment for NC. Extent of surgical resection, initial radiotherapy and chemotherapy may have positive impact on OS rate, although strong conclusion cannot be drawn because of the insufficient number of cases. Comprehensive protocol for sarcoma (SSG IX) and targeted therapy may offer promising options for the treatment of NC.

\section{Acknowledgments}

Funding: None.

\section{Footnote}

Reporting Checklist: The authors have completed the Narrative Review reporting checklist. Available at http:// dx.doi.org/10.21037/tcr-20-1884

Peer Review File: Available at http://dx.doi.org/10.21037/tcr20-1884

Conflicts of Interest: All authors have completed the ICMJE uniform disclosure form (available at http://dx.doi. org/10.21037/tcr-20-1884). The authors have no conflicts of interest to declare.

Ethical Statement: The authors are accountable for all aspects of the work in ensuring that questions related to the accuracy or integrity of any part of the work are appropriately investigated and resolved.

Open Access Statement: This is an Open Access article distributed in accordance with the Creative Commons Attribution-NonCommercial-NoDerivs 4.0 International License (CC BY-NC-ND 4.0), which permits the noncommercial replication and distribution of the article with the strict proviso that no changes or edits are made and the original work is properly cited (including links to both the formal publication through the relevant DOI and the license). See: https://creativecommons.org/licenses/by-nc-nd/4.0/.

\section{References}

1. Kees UR, Mulcahy MT, Willoughby ML. Intrathoracic carcinoma in an 11-year-old girl showing a translocation 
t(15;19). Am J Pediatr Hematol Oncol 1991;13:459-64.

2. Sirohi D, Garg K, Simko JP, et al. Renal NUT carcinoma: a case report. Histopathology 2018;72:528-30.

3. Shehata BM, Steelman CK, Abramowsky CR, et al. NUT midline carcinoma in a newborn with multiorgan disseminated tumor and a 2-year-old with a pancreatic/ hepatic primary. Pediatr Dev Pathol 2010;13:481-5.

4. Esteves G, Ferreira J, Afonso R, et al. HDAC Overexpression in a NUT Midline Carcinoma of the Parotid Gland with Exceptional Survival: A Case Report. Head Neck Pathol 2020. [Epub ahead of print].

5. French CA, Kutok JL, Faquin WC, et al. Midline carcinoma of children and young adults with NUT rearrangement. J Clin Oncol 2004;22:4135-9.

6. Seim NB, Philips RHW, Schoenfield L, et al. NUT Midline Carcinoma of the Sublingual Gland: Clinical Presentation and Review. Head Neck Pathol 2017;11:460-8.

7. Roy S, Ayala G. Nuclear Protein in Testis (NUT) Midline Carcinoma in the Femur: A Unique Presentation. Am J Clin Pathol 2018;150:S27.

8. Mengoli MC, Longo FR, Fraggetta F, et al. The 2015 World Health Organization Classification of lung tumors: New entities since the 2004 Classification. Pathologica 2018;110:39-67.

9. Bauer DE, Mitchell CM, Strait KM, et al. Clinicopathologic features and long-term outcomes of NUT midline carcinoma. Clin Cancer Res 2012;18:5773-9.

10. French CA. Demystified molecular pathology of NUT midline carcinomas. J Clin Pathol 2010;63:492-6.

11. Evans AG, French CA, Cameron MJ, et al. Pathologic characteristics of nut midline carcinoma arising in the mediastinum. Am J Surg Pathol 2012;36:1222-7.

12. French CA. Pathogenesis of NUT midline carcinoma. Annu Rev Pathol 2012;7:247-65.

13. Lee JK, Louzada S, An Y, et al. Complex chromosomal rearrangements by single catastrophic pathogenesis in NUT midline carcinoma. Ann Oncol 2017;28:890-7.

14. Bishop JA, French CA, Ali SZ. Cytopathologic features of NUT midline carcinoma: A series of 26 specimens from 13 patients. Cancer Cytopathol 2016;124:901-8.

15. Oliveira LJC, Gongora ABL, Latancia MT, et al. The first report of molecular characterized BRD4-NUT carcinoma in Brazil: a case report. J Med Case Rep 2019;13:279.

16. Shiota H, Barral S, Buchou T, et al. NUT Directs p300Dependent, Genome-Wide H4 Hyperacetylation in Male Germ Cells. Cell Rep 2018;24:3477-87.e6.
17. French CA, Rahman S, Walsh EM, et al. NSD3NUT fusion oncoprotein in NUT midline carcinoma: implications for a novel oncogenic mechanism. Cancer Discov 2014;4:928-41.

18. French CA, Ramirez CL, Kolmakova J, et al. BRD-NUT oncoproteins: a family of closely related nuclear proteins that block epithelial differentiation and maintain the growth of carcinoma cells. Oncogene 2008;27:2237-42.

19. Alekseyenko AA, Walsh EM, Zee BM, et al. Ectopic protein interactions within BRD4-chromatin complexes drive oncogenic megadomain formation in NUT midline carcinoma. Proc Natl Acad Sci U S A 2017;114:E4184-92.

20. Shatavi S, Fawole A, Haberichter K, et al. Nuclear protein in testis (NUT) midline carcinoma with a novel threeway translocation $(4 ; 15 ; 19)(q 13 ; q 14 ; p 13.1)$. Pathology 2016;48:620-3.

21. Stevens TM, Morlote D, Xiu J, et al. NUTM1-rearranged neoplasia: a multi-institution experience yields novel fusion partners and expands the histologic spectrum. Mod Pathol 2019;32:764-73.

22. Diolaiti D, Dela Cruz FS, Gundem G, et al. A recurrent novel MGA-NUTM1 fusion identifies a new subtype of high-grade spindle cell sarcoma. Cold Spring Harb Mol Case Stud 2018;4:a003194..

23. Dickson BC, Sung YS, Rosenblum MK, et al. NUTM1 Gene Fusions Characterize a Subset of Undifferentiated Soft Tissue and Visceral Tumors. Am J Surg Pathol 2018;42:636-45.

24. French CA, Miyoshi I, Kubonishi I, et al. BRD4-NUT fusion oncogene: a novel mechanism in aggressive carcinoma. Cancer Res 2003;63:304-7.

25. Stirnweiss A, Oommen J, Kotecha RS, et al. Moleculargenetic profiling and high-throughput in vitro drug screening in NUT midline carcinoma-an aggressive and fatal disease. Oncotarget 2017;8:112313-29.

26. Chau NG, Ma C, Danga K, et al. An Anatomical Site and Genetic-Based Prognostic Model for Patients With Nuclear Protein in Testis (NUT) Midline Carcinoma: Analysis of 124 Patients. JNCI Cancer Spectr 2020;4:pkz094.

27. Alekseyenko AA, Walsh EM, Wang X, et al. The oncogenic BRD4-NUT chromatin regulator drives aberrant transcription within large topological domains. Genes Dev 2015;29:1507-23.

28. Zee BM, Dibona AB, Alekseyenko AA, et al. The Oncoprotein BRD4-NUT Generates Aberrant Histone Modification Patterns. PLoS One 2016;11:e163820.

29. Dey A, Chitsaz F, Abbasi A, et al. The double 
bromodomain protein Brd4 binds to acetylated chromatin during interphase and mitosis. Proc Natl Acad Sci U S A 2003;100:8758-63.

30. Loven J, Hoke HA, Lin CY, et al. Selective inhibition of tumor oncogenes by disruption of super-enhancers. Cell 2013;153:320-34.

31. Mertz JA, Conery AR, Bryant BM, et al. Targeting MYC dependence in cancer by inhibiting BET bromodomains. Proc Natl Acad Sci U S A 2011;108:16669-74.

32. Puissant A, Frumm SM, Alexe G, et al. Targeting MYCN in neuroblastoma by BET bromodomain inhibition. Cancer Discov 2013;3:308-23.

33. Shi J, Vakoc CR. The mechanisms behind the therapeutic activity of BET bromodomain inhibition. Mol Cell 2014;54:728-36.

34. Wang R, Liu W, Helfer CM, et al. Activation of SOX2 expression by BRD4-NUT oncogenic fusion drives neoplastic transformation in NUT midline carcinoma. Cancer Res 2014;74:3332-43.

35. Grayson AR, Walsh EM, Cameron MJ, et al. MYC, a downstream target of BRD-NUT, is necessary and sufficient for the blockade of differentiation in NUT midline carcinoma. Oncogene 2014;33:1736-42.

36. Wang R, Cao XJ, Kulej K, et al. Uncovering BRD4 hyperphosphorylation associated with cellular transformation in NUT midline carcinoma. Proc Natl Acad Sci U S A 2017;114:E5352-61.

37. Leis O, Eguiara A, Lopez-Arribillaga E, et al. Sox2 expression in breast tumours and activation in breast cancer stem cells. Oncogene 2012;31:1354-65.

38. Wu F, Zhang J, Wang P, et al. Identification of two novel phenotypically distinct breast cancer cell subsets based on Sox2 transcription activity. Cell Signal 2012;24:1989-98.

39. Ors-Kumoglu G, Gulce-Iz S, Biray-Avci C. Therapeutic microRNAs in human cancer. Cytotechnology 2019;71:411-25.

40. Braconi C, Henry JC, Kogure T, et al. The role of microRNAs in human liver cancers. Semin Oncol 2011;38:752-63.

41. Pathak E, Bhavya, Mishra D, et al. Deciphering the Role of microRNAs in BRD4-NUT Fusion Gene Induced NUT Midline Carcinoma. Bioinformation 2017;13:209-13.

42. Tonouchi E, Gen Y, Muramatsu T, et al. miR-3140 suppresses tumor cell growth by targeting BRD4 via its coding sequence and downregulates the BRD4-NUT fusion oncoprotein. Sci Rep 2018;8:4482.

43. Reynoird N, Schwartz BE, Delvecchio M, et al.
Oncogenesis by sequestration of CBP/p300 in transcriptionally inactive hyperacetylated chromatin domains. EMBO J 2010;29:2943-52.

44. Sun K, Atoyan R, Borek MA, et al. Dual HDAC and PI3K Inhibitor CUDC-907 Downregulates MYC and Suppresses Growth of MYC-dependent Cancers. Mol Cancer Ther 2017;16:285-99.

45. Liao S, Maertens O, Cichowski K, et al. Genetic modifiers of the BRD4-NUT dependency of NUT midline carcinoma uncovers a synergism between BETis and CDK4/6is. Genes Dev 2018;32:1188-200.

46. Elkhatib SK, Neilsen BK, Sleightholm RL, et al. A 47-year-old woman with nuclear protein in testis midline carcinoma masquerading as a sinus infection: a case report and review of the literature. J Med Case Rep 2019;13:57.

47. Albrecht T, Harms A, Roessler S, et al. NUT carcinoma in a nutshell: A diagnosis to be considered more frequently. Pathol Res Pract 2019;215:152347.

48. Suzuki S, Kurabe N, Ohnishi I, et al. NSD3-NUTexpressing midline carcinoma of the lung: first characterization of primary cancer tissue. Pathol Res Pract 2015;211:404-8.

49. Baras AS, Naidoo J, Hann CL, et al. Rediagnosis of Lung Cancer as NUT Midline Carcinoma Based on Clues From Tumor Genomic Profiling. J Natl Compr Canc Netw 2018;16:467-72.

50. Klijanienko J, Le Tourneau C, Rodriguez J, et al. Cytological features of NUT midline carcinoma arising in sino-nasal tract and parotid gland: Report of two new cases and review of the literature. Diagn Cytopathol 2016;44:753-6.

51. Arimizu K, Hirano G, Makiyama C, et al. NU'T carcinoma of the nasal cavity that responded to a chemotherapy regimen for Ewing's sarcoma family of tumors: a case report. BMC Cancer 2018;18:1134.

52. Ueki H, Maeda N, Sekimizu M, et al. A case of NUT midline carcinoma with complete response to gemcitabine following cisplatin and docetaxel. J Pediatr Hematol Oncol 2014;36:e476-80.

53. Aizawa H, Yamada S, Sakai H, et al. Nuclear protein of the testis midline carcinoma in the oral cavity: retrospective review of those initially diagnosed as poorly differentiated squamous cell carcinoma using an anti-C52B1 antibody. Int J Oral Maxillofac Surg 2019;48:1265-72.

54. Teo M, Crotty P, O'Sullivan M, et al. NUT midline carcinoma in a young woman. J Clin Oncol 2011;29:e336-9.

55. Agaimy A, Fonseca I, Martins C, et al. NUT Carcinoma 
of the Salivary Glands: Clinicopathologic and Molecular Analysis of 3 Cases and a Survey of NUT Expression in Salivary Gland Carcinomas. Am J Surg Pathol 2018;42:877-84.

56. D'Souza JN, Notz G, Bogdasarian RN, et al. Orbital Involvement by NUT Midline Carcinoma. Ophthalmic Plast Reconstr Surg 2015;31:e147-50.

57. Chau NG, Hurwitz S, Mitchell CM, et al. Intensive treatment and survival outcomes in NUT midline carcinoma of the head and neck. Cancer 2016;122:3632-40.

58. Giridhar P, Mallick S, Kashyap L, et al. Patterns of care and impact of prognostic factors in the outcome of NUT midline carcinoma: a systematic review and individual patient data analysis of 119 cases. Eur Arch Otorhinolaryngol 2018;275:815-21.

59. Beesley AH, Stirnweiss A, Ferrari E, et al. Comparative drug screening in NUT midline carcinoma. Br J Cancer 2014;110:1189-98.

60. Storck S, Kennedy AL, Marcus KJ, et al. Pediatric NUTmidline carcinoma: Therapeutic success employing a sarcoma based multimodal approach. Pediatr Hematol Oncol 2017;34:231-7.

61. Mertens F, Wiebe T, Adlercreutz C, et al. Successful treatment of a child with $\mathrm{t}(15 ; 19)$-positive tumor. Pediatr Blood Cancer 2007;49:1015-7.

62. French CA. Small-Molecule Targeting of BET Proteins in Cancer. Adv Cancer Res 2016;131:21-58.

63. Bhadury J, Nilsson LM, Muralidharan SV, et al. BET and HDAC inhibitors induce similar genes and biological effects and synergize to kill in Myc-induced murine lymphoma. Proc Natl Acad Sci U S A 2014;111:E2721-30.

64. Sahai V, Redig AJ, Collier KA, et al. Targeting BET bromodomain proteins in solid tumors. Oncotarget 2016;7:53997-4009.

65. Zhu X, Park S, Lee WK, et al. Potentiated anti-tumor effects of BETi by MEKi in anaplastic thyroid cancer. Endocr Relat Cancer 2019;26:739-50.

66. Stathis A, Zucca E, Bekradda M, et al. Clinical Response of Carcinomas Harboring the BRD4-NUT Oncoprotein to the Targeted Bromodomain Inhibitor OTX015/MK8628. Cancer Discov 2016;6:492-500.

67. Lewin J, Soria JC, Stathis A, et al. Phase Ib Trial With Birabresib, a Small-Molecule Inhibitor of Bromodomain and Extraterminal Proteins, in Patients With Selected Advanced Solid Tumors. J Clin Oncol 2018;36:3007-14.

68. Piha-Paul SA, Hann CL, French CA, et al. Phase 1 Study of Molibresib (GSK525762), a Bromodomain and Extra-Terminal Domain Protein Inhibitor, in NUT Carcinoma and Other Solid Tumors. JNCI Cancer Spectr 2020;4:pkz093.

69. Torre M, Qian X. Cytopathologic and immunophenotypic changes in NUT midline carcinoma after targeted therapy. Cancer Cytopathol 2017;125:70.

70. Sui S, Zhang J, Xu S, et al. Ferritinophagy is required for the induction of ferroptosis by the bromodomain protein BRD4 inhibitor (+)-JQ1 in cancer cells. Cell Death Dis 2019;10:331.

71. Li F, Yang C, Zhang HB, et al. BET inhibitor JQ1 suppresses cell proliferation via inducing autophagy and activating LKB1/AMPK in bladder cancer cells. Cancer Med 2019;8:4792-805.

72. Liu K, Zhou Z, Gao H, et al. JQ1, a BET-bromodomain inhibitor, inhibits human cancer growth and suppresses PD-L1 expression. Cell Biol Int 2019;43:642-50.

73. Nakagawa A, Adams CE, Huang Y, et al. Selective and reversible suppression of intestinal stem cell differentiation by pharmacological inhibition of BET bromodomains. Sci Rep 2016;6:20390.

74. Sahni JM, Gayle SS, Bonk KL, et al. Bromodomain and Extraterminal Protein Inhibition Blocks Growth of Triplenegative Breast Cancers through the Suppression of Aurora Kinases. J Biol Chem 2016;291:23756-68.

75. Marcotte R, Sayad A, Brown KR, et al. Functional Genomic Landscape of Human Breast Cancer Drivers, Vulnerabilities, and Resistance. Cell 2016;164:293-309.

76. Stratikopoulos EE, Dendy M, Szabolcs M, et al. Kinase and BET Inhibitors Together Clamp Inhibition of PI3K Signaling and Overcome Resistance to Therapy. Cancer Cell 2015;27:837-51.

77. Shu S, Lin CY, He HH, et al. Response and resistance to BET bromodomain inhibitors in triple-negative breast cancer. Nature 2016;529:413-7.

78. Schwartz BE, Hofer MD, Lemieux ME, et al. Differentiation of NUT midline carcinoma by epigenomic reprogramming. Cancer Res 2011;71:2686-96.

79. Maher OM, Christensen AM, Yedururi S, et al. Histone deacetylase inhibitor for NUT midline carcinoma. Pediatr Blood Cancer 2015;62:715-7.

80. Brägelmann J, Dammert MA, Dietlein F, et al. Systematic Kinase Inhibitor Profiling Identifies CDK9 as a Synthetic Lethal Target in NUT Midline Carcinoma. Cell Rep 2017;20:2833-45.

81. Ding T, Wang Y, Zhao T, et al. NUT midline carcinoma in the right orbit: a case report. Cancer Biol Ther 2019;20:1091-6. 
82. Lemelle L, Pierron G, Freneaux P, et al. NUT carcinoma in children and adults: A multicenter retrospective study. Pediatr Blood Cancer 2017. doi: 10.1002/pbc.26693.

83. Wang H, Weiss VL, Hoffman RD, et al. Salivary Gland

Cite this article as: Wang S, Li J, Tong W, Li H, Feng Q, Teng B. Advances in the pathogenesis and treatment of nut carcinoma: a narrative review. Transl Cancer Res 2020;9(10):6505-6515. doi: $10.21037 /$ tcr-20-1884
NUT Carcinoma with Prolonged Survival in Children: Case Illustration and Systematic Review of Literature. Head Neck Pathol 2020. [Epub ahead of print]. 